\title{
STUDIES ON THE APPLICATION OF HOLLOW FIBER MEMBRANES IN THE FIELD OF ULTRAFILTRATION
}

\author{
LAURENȚIU TATARU ${ }^{* 1}$, VALENTIN NEDEFF ${ }^{1,2}$, NARCIS BARSAN ${ }^{1}$, \\ MIRELA PANAINTE-LEHADUS ${ }^{1}$, EMILIAN MOSNEGUTU ${ }^{1}$, \\ DANA-ALEXANDRA CHITIMUS ${ }^{1}$ \\ 1 "Vasile Alecsandri" University of Bacau, Calea Marasesti 157, Bacau, 600115, Romania \\ ${ }^{2}$ Academy of Agricultural and Forestry Sciences "Gheorghe Ionescu Sisesti”, \\ B-dul. Marasti nr. 61, Sector 1, Bucuresti, Romania
}

\begin{abstract}
This study is a review of knowledge and understanding of organic fiber membrane behavior in wastewater ultrafiltration processes. Current research is increasingly focusing on the use of state-of-the-art technologies for the elimination of pollutants in water and the use of membranes. This study focuses on testing hollow fiber organic membranes for the ultrafiltration process as a precursor to osmosis processes. The major advantages of ultrafiltration are the elimination of many small organic and inorganic compounds from the water, which cannot be eliminated in microfiltration processes, offering superior quality water. This review highlights the effectiveness of organic membranes from hollow fibers in relation to the dependence between filtering parameters and those related to the membrane type structure, respectively the membrane structure of the polyacrylonitrile. The results of the study on the testing of such membranes have shown that filtration efficiency increases inversely with the degree of fouling on the surface of the membrane; the permeate quality being superior in the early stages of the membrane lifecycle, decreasing with increasing use time. In other words, the aging of the membrane decreases the volume of the permeate and at the same time changes the dependence of the parameters: pressure, temperature, flow if it is desired to obtain the same amount of permeate. Finding the best solutions for streamlining the membrane structure and running under the best conditions will be presented in the current paper.
\end{abstract}

Keywords: ultrafiltration, PAN hollow fiber membrane, chemical compounds rejection, pesticides, recovery of citrus oil

\section{INTRODUCTION}

Water pollution as a result of natural and anthropogenic activities limits the presence in large quantities of water sources for consumption. Another cause of this limitation is the inefficient use of water in different activities. A solution that helps to reduce the consumption water crisis is the use of membrane technologies for water filtration that are thought to be more and more effective [1-6].

Wastewater filtration membranes are of several types but research shows that the polymeric ones have the greatest advantages, namely: low acquisition and maintenance costs, ease of operation but also very flexible and easy assembling [7].

\footnotetext{
Corresponding author, email: tataru_lauri@yahoo.com

(C) 2016 Alma Mater Publishing House
} 
Polymeric membranes are usually constructed in flat or tubular form with hollow fibers. The latter have the advantage of achieving greater water productivity per unit volume and the procedure for manufacturing the membrane module is simpler [8].

To be as efficient as possible, a membrane used in ultrafiltration processes should have the following features: as much as possible rejection of the concentrated portion of the feed water, high resistance to the chemical agents used, high mechanical strength, allowing the passage of a large stream of water through the surface of the membrane, anti-fouling properties, respectively hydrophobicity [9].

Over the years, in recent years, ultrafiltration membranes with different shapes and structures have been developed to further retard the phenomenon of clogging of the filtering surface but also to increase mechanical strength during operation with this type of membrane [10-12]. The most handy solution for removing the material from the membrane pores in both ultrafiltration and microfiltration remains countercurrent flushing, altered by the modification of the membrane structure phase [13-16].

Another problem that can be at least improved through hollow fiber membranes is that of pesticide use in agriculture. More specifically, nowadays, in order to obtain large quantities of food, we use in excess all sorts of harmful solutions, especially human health [16].

In the case of citrus, pesticides accumulate the most in the shell, which leads to their mixing with oils that can be extracted for different uses, so a clear poisoning [16].

Hollow fiber membranes can also be used successfully in separating citrus pesticide oils. The increasing use of these types of membranes is more and more developed because they can be easily obtained from homogeneous materials, polymeric solutions and oligosaccharides such as cyclodextrin, and their cleaning can be done easily with alkaline solutions [16]. Another advantage of these membranes is given by the filter surface which can be extended on the unit of volume and at the same time the lack of additional material to support the membrane [17, $18]$.

For the manufacture of this tipe of membranes, the most suitable polymers are polyimidize, polybenzimidazole and polyacrylonitrile, which are also most effective in the field of ultrafiltration and nanofiltration processes [1921].

Selectivity and permeability are essential elements in determining the efficiency of a membrane because these parameters describe one of the most important features: the pore size dimension. As their size increases, water permeability increases but decreases selectivity and material retention [22, 23].

Hermia [22] proposed two models of membrane pores filling (Figure1), respectively when the particles are smaller than the size of the pores and while they are deposited on the membrane channels and the second model when the particles subjected to the filtration are larger in diameter and thus favored effective pore blocking.

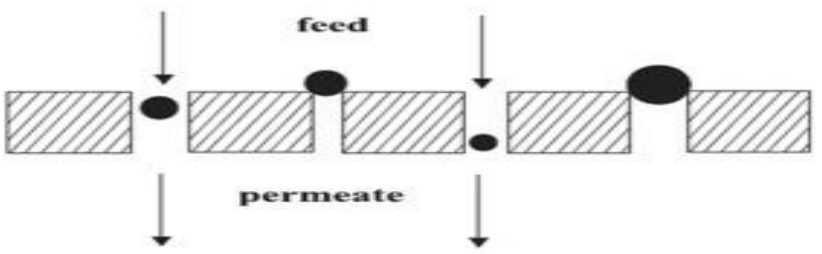

(a) Complete pore blocking

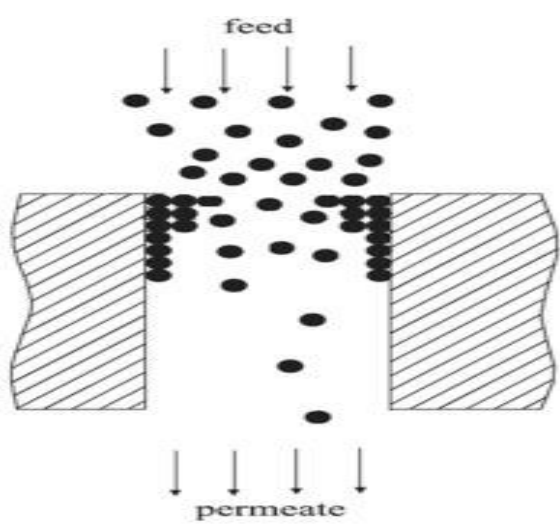

(b) Pore constriction

Fig. 1. Membrane fouling patterns [22]:

a) blocking pores; b) Strangulation of the active filter diameter. 
Separation performances can be obtained by several methods for the modification of hollow fibers, among which: application of additives [24, 25], operation with thermal treatments [26-31], grafting [30], mixing [31] and crosslinking [32].

\section{APPLYING ORGANIC MEMBRANES TO HOLLOW FIBERS IN ULTRAFILTRATION PROCESSES}

The hollow fiber ultrafiltration membranes present in this paper focus on reducing or, as far as possible, eliminating organic and inorganic compounds in the filtration waters. Their efficiency depends on the results obtained as a dependency relation both between the parameters of the installations present in the study and the parameters of the membranes [34].

Regardless of the field of use, the membranes used are polyacrylonitrile. Polyacrylonitrile (PAN) fibers were obtained by phase inversion technique [34, 35], having an inner and outer diameter different depending on the volume and the filter area. The module is provided with a glass tube that incorporates the membrane and the fluid flow respectively. The membrane under study has different surface and length (effective filtration area) [36].

In the following, various directions for using this type of membrane in ultrafiltration will be presented.

\subsection{Retention of pesticides in citrus oils}

The plant (Figure 2) is provided with a supply tank containing pesticide-mixed oils, a coil cooler for controlling the temperature of the liquid supply, a membrane module, a pump feeding the membrane of the module, two manometers for recording the pressure at the inlet or exit of the module, the permeate reservoir and a pressure regulating valve.

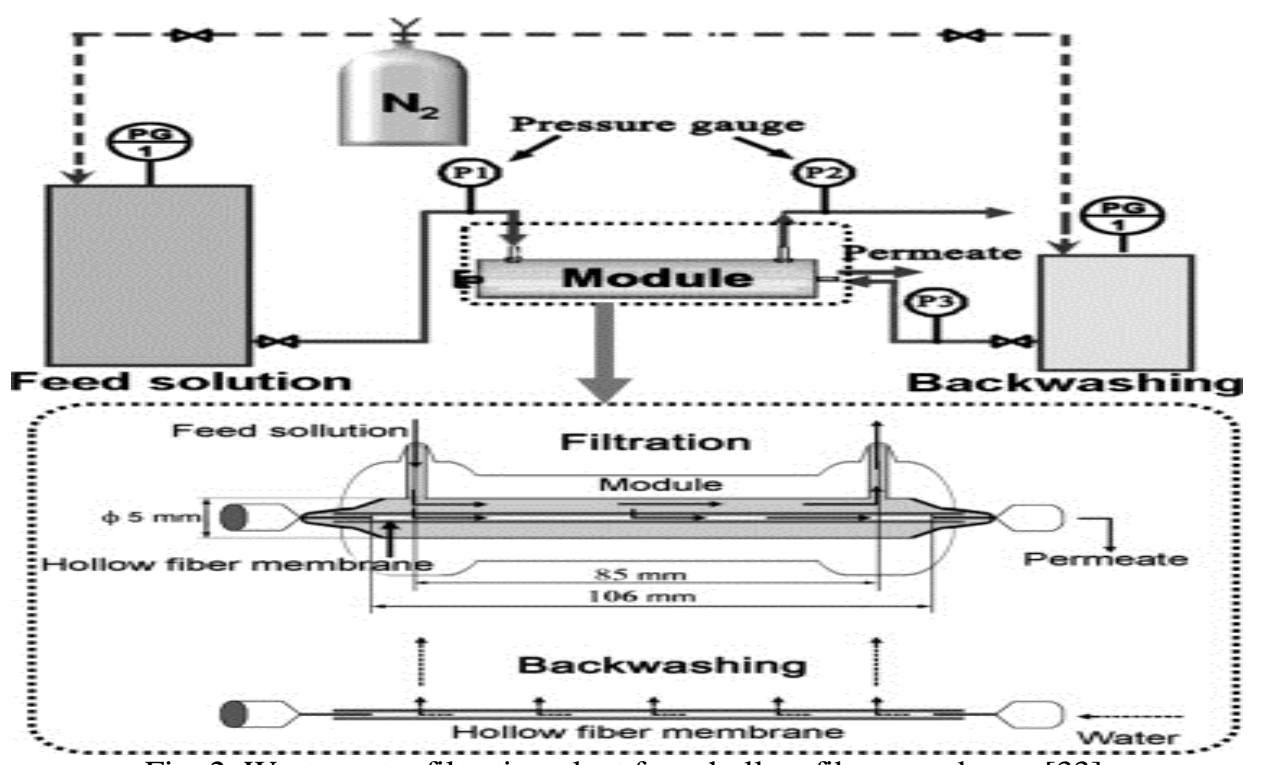

Fig. 2. Waste water filtration plant from hollow fiber membrane [33]

Repeated tests have been carried out with permeate recycling and recirculation of the concentrated phase in the supply tank under already established operating conditions, respectively a 1.4 bar trans-membrane pressure at a temperature of about $25^{\circ} \mathrm{C}$. It has been established from the beginning, the permeate collection time, then measured in the unit of time, expressed in $\mathrm{L} / \mathrm{m}^{2} / \mathrm{h}[36]$.

\subsubsection{Efficiency of organic hollow fiber membranes in terms of pore permeability}

C. Cao, et al. [37] developed a model of water permeability through the membrane pores, and the results of the model concluded that a higher molecular weight implies a decrease in permeate because the material passing through the pore opening can be stored more easily (Figure 3). 
In Figure 3.a. it is observed that with the increase in the absorption of the filtration liquid, both the permeability and the molecular weight decrease. In part, b of the figure the distribution of the pore size narrows as the absorption speed increases. This increase in velocity proves that the polymer chains have a better alignment [37]. The decrease in membrane permeability is due to fiber stretching as a result of long-term heating and crosslinking. In other words, there is a heat-induced densification at the fiber level [38-40].

(a)

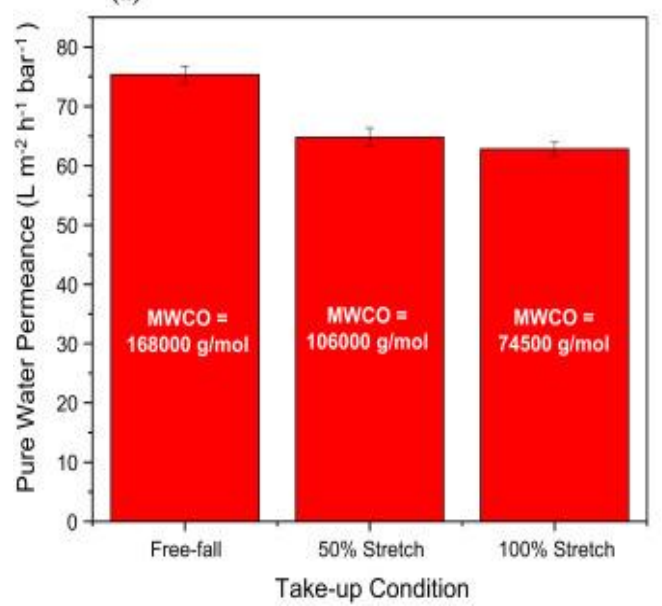

(b)

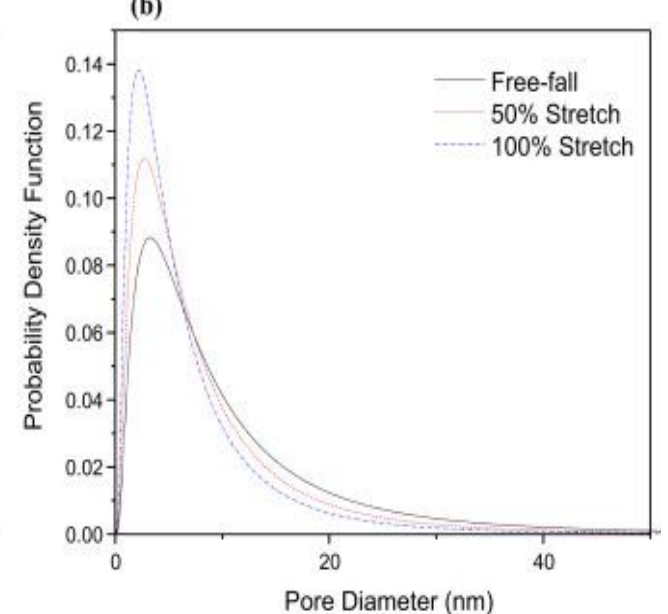

Fig. 3. Membrane permeability by molecular weight [37].

In Figure 4, sections a), b), and c) show the pore size distribution at the highest level. In other words, fiber crosslinking showed the highest performance after 18 hours, which means excellent mechanical strength in the membrane [42-45].
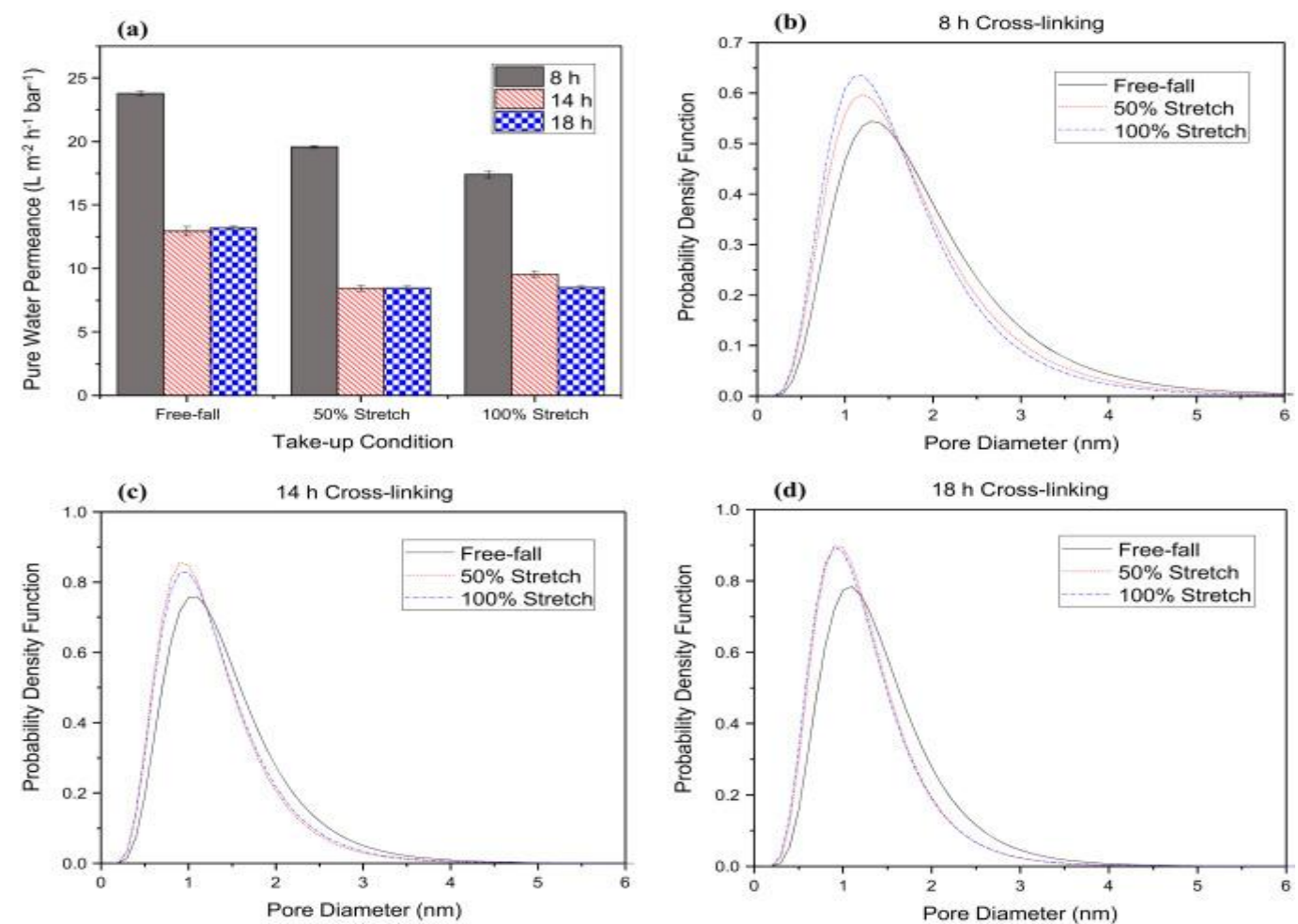

Fig. 4. Water permeability and pore size distribution PAN membrane after 8, 14, 18 hours [41].

After a period of about 18 hours, the fibers can reduce their volume by up to $10 \%$, which means that the pore size is also reduced, thus a decrease in membrane permeability [39]. 


\subsubsection{Controlling the fouling process of hollow fiber membranes}

K. Parameshwaran et al. [46] have successfully confirmed that the method of countercurrent washing of the membranes remains a solution that requires increased attention even if the matter deposited at the level of pores cannot be completely eliminated.

A very good solution for membrane cleaning after filtering is the backwash method, respectively countercurrent washing with the resultant permeate. In the work done by these authors [46], washing was done every 20 minutes, in a flow of $70 \mathrm{~L} / \mathrm{m}^{2} / \mathrm{h}$ permeate, with aeration for two minutes before resuming each filtration process.

The results showed that no matter how effective this membrane cleaning method is, the particles cannot be eliminated because they have been deposited on the surface or on the surface of the membrane. This has shown an increase in transmembrane pressure (Figure 5) after each wash cycle [46].

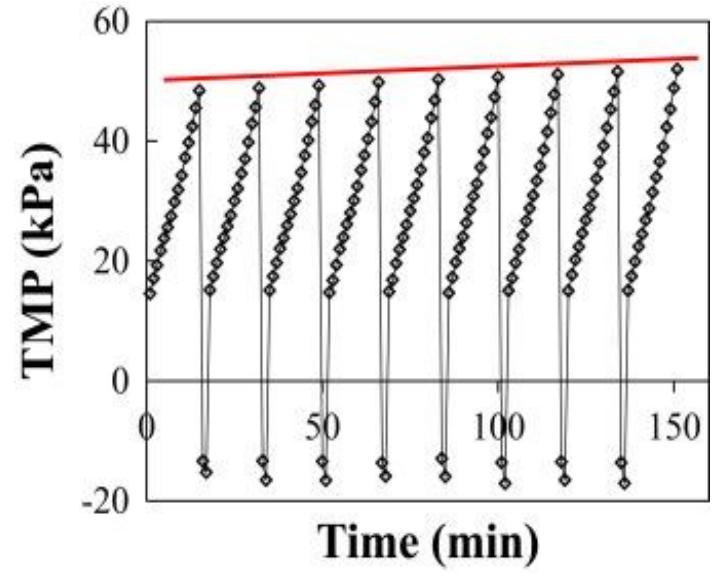

a)

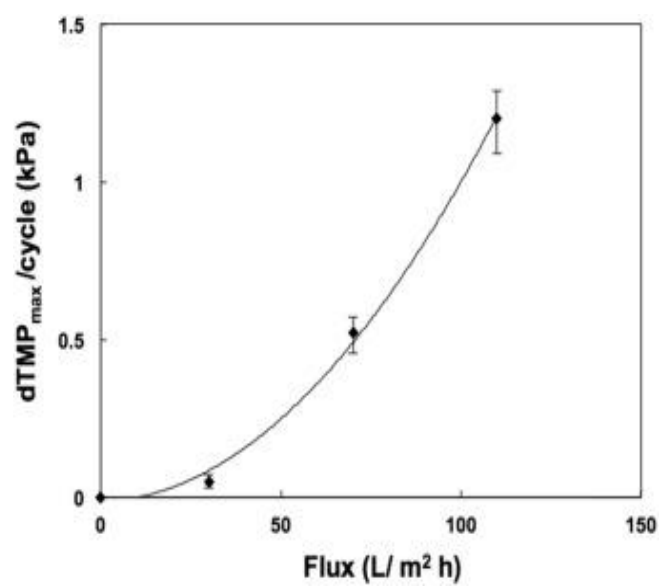

b)

Fig. 5. Trans-membrane pressure [46]:

a) The pressure variation in the time unit of countercurrent washing, followed by aeration for two minutes at a flow rate of $70 \mathrm{~L} / \mathrm{m}^{2} / \mathrm{h}$; b) Change of trans-membrane pressure at each backwash cycle relative to permeate flow.

After experiments with the main purpose of extracting pesticides from citrus oils, it was also demonstrated that the flow of permeate was somewhat constant although the weight of the oil was reduced up to five times as much under the operating conditions of the set installation, respectively: trans-membrane pressure of 1.4 bar, $20^{\circ} \mathrm{C}$ and axial feed flow (Figure 6) [47].

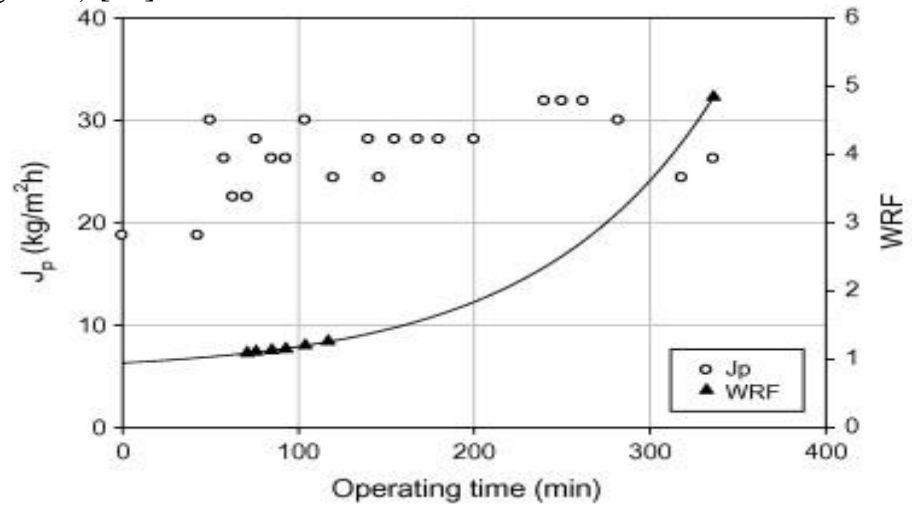

Fig. 6. Weight-reducing factor in citrus oil filtration using organic hollow fiber-membranes [47].

The results of the study showed that the permeate flow was different for the filtration of mandarin and lemon oil (Figure 7), the permeate obtained in the case of mandarin oil was twice as much as lemon oil and almost 30 $\mathrm{L} / \mathrm{m}^{2} / \mathrm{h}$ respectively. The increase in permeate flow was mainly due to the increase in axial flow in the feed, 
which implies that polarization of the concentration can be diminished by the shear effect from the surface of the membrane [47].

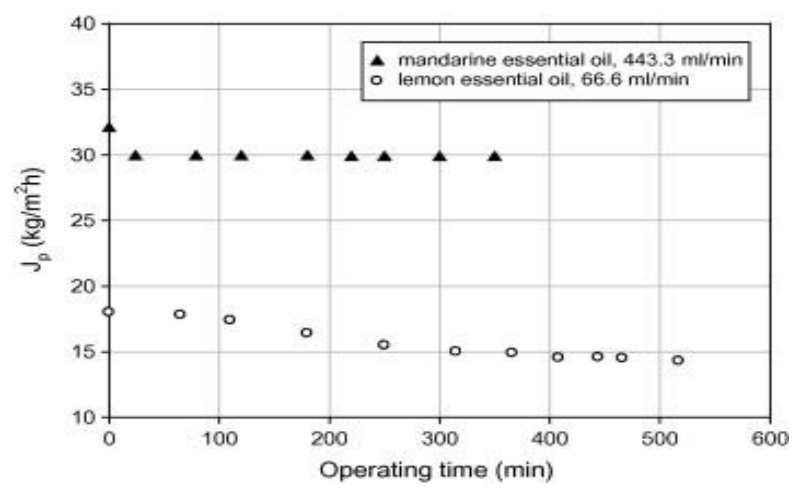

Fig. 7. Permeate flow time for the filtration of mandarin and lemon oil through a cyclodextrin-loaded hollow fiber membrane under established operating conditions [47].

\subsection{Use of hollow fiber membranes in the juice industry}

Mohammad et al. [49] tested hollow fiber organic membranes to see the effectiveness of removal of pollutants from juices, such as yeasts, colloids, certain microorganisms but also molds (Figure 8).

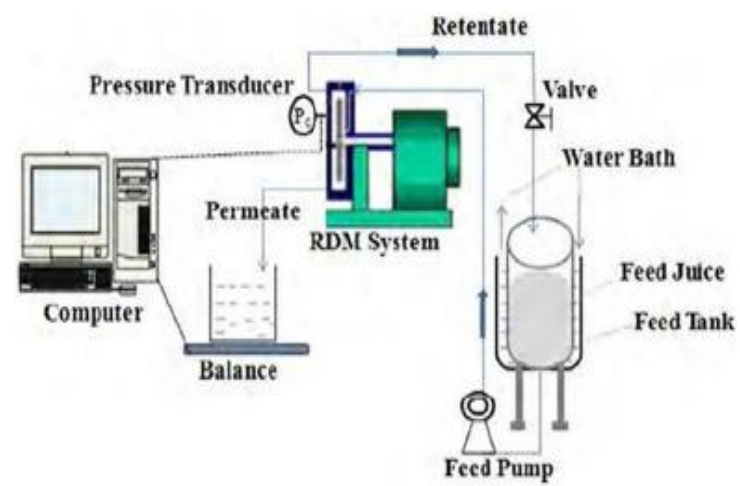

Fig. 8. Filtration of juices through hollow fiber membrane [52].

To increase filtration efficiency, the authors used certain pectinase-based mixtures and thus managed to increase permeate flow and concentrate recovery. Although proteins and fibers had the highest degree of fouling on the surface of the membrane in juice filtration, researchers achieved a yield of nearly $95 \%$ with product recovery (Figure 9) due to decreased viscosity [53].

To reduce blocking membrane pores, they used the ultrasonic vibration method [50] and pulse wash [51].

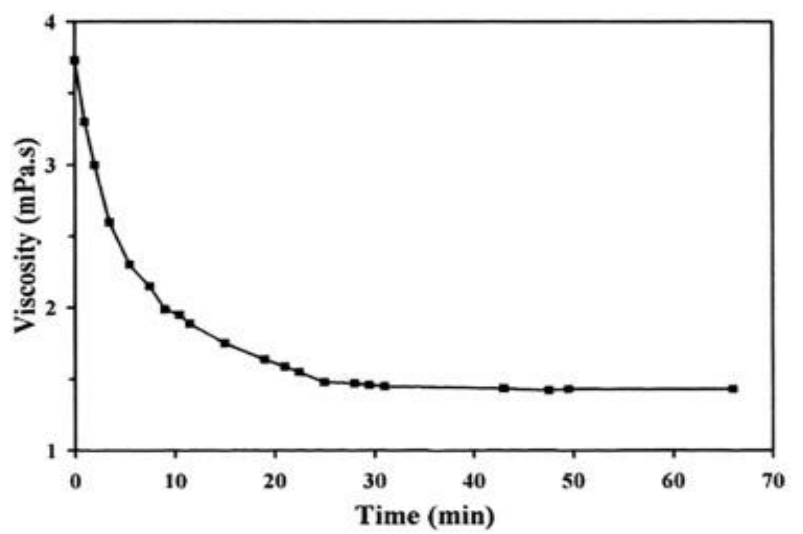

Fig. 9. Viscosity variation by pectinase [53]. 


\subsection{Behavior of hollow fiber membranes in the separation of photocatalysts}

Guoliang Zhang et al. [54] 4 types of hollow fiber membranes were used (Figure 10): one of polyacrylonitrile and 3 polyether sulfone with a pore size of 0.2 and $0.4 \mu \mathrm{m}$, in a process for separating $\mathrm{TiO}_{2}$ photocatalysts, and attempted to determine the time required for membrane fouling as a result of the deposition of these particles in membrane pores. The tested membranes had a molecular weight of 600,000 Da.

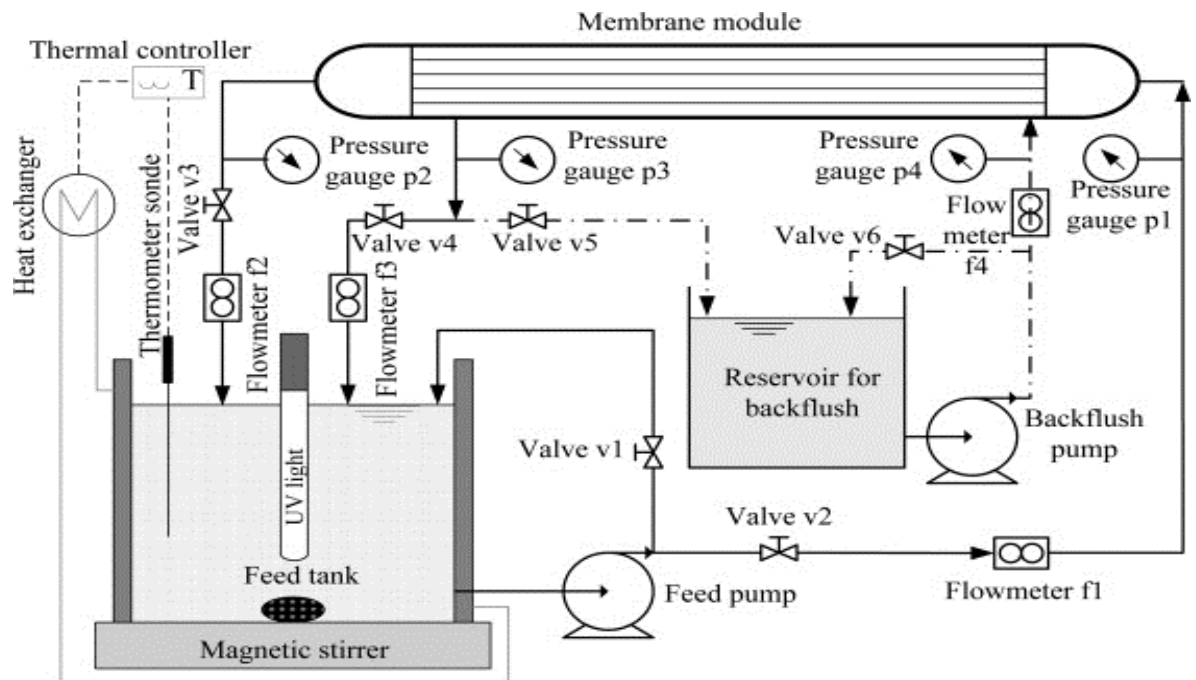

Fig. 10. The photocatalytic separation process of $\mathrm{TiO} 2$ through hollow fiber membranes [54].

After the experiments, it was found that $\mathrm{TiO}_{2}$ particles that were about the same size blocked the pores, favoring a rapid decline in permeate flux and increased transmembrane pressure. Backwash was not $100 \%$ efficient due to strong adhesion to the surface of the membrane [54].

The working conditions were the same for all 4 membranes, but the normalized flow was completely different (Figure 11), for the PAN membrane, this being almost constant but for the other three membranes, varying significantly [54]. The reason for the flow varies clearly remains the blockage of the membrane pores due in particular to the properties of each membrane used in the experiments [55].

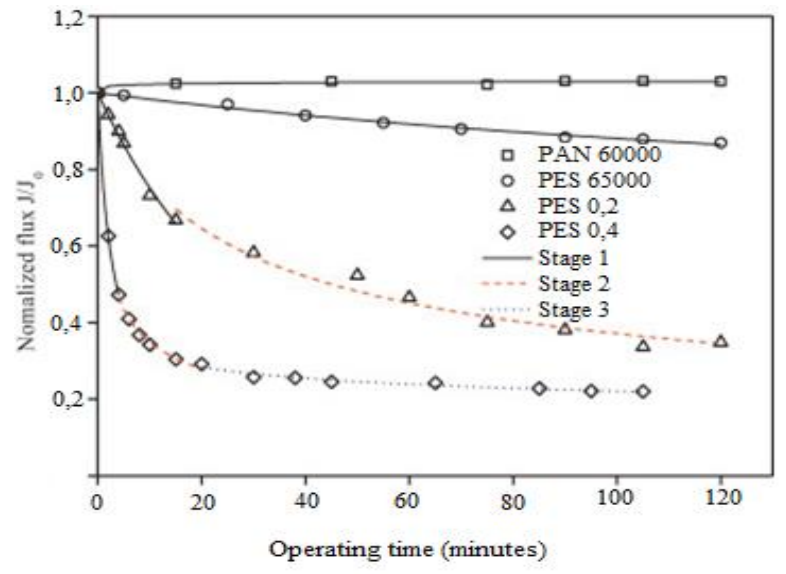

Fig. 11. Flow variation with in relation to the $\mathrm{TiO}_{2}$ selection time [54].

\section{RESULTS AND DISCUSSION}

The ultra-filtration system MP 90 (Figure 12) is an ultrafiltration plant provided with an organic hollow fiber membrane module with the following features [57]:

- membrane module;

- multicellular vertical feed pump;

- plastic flowmeters; 
- display of ASCON C1 temperature and pressure;

- permeate bowl;

- gauges;

- 3 pressure sensors ENDRESS + HAUSER Cerebar (PT1: 0-6 bar, PT2 and PT3: 0-4 bar);

- 3 BAUMER MEX 3 pressure gauges (0-2.5 bar);

- BURKERT electro-valve (solenoid) (temperature changer);

- Safety valve (stainless steel valve calibrated at 5 bar);

- Sample probe: 3 electrodes S8 CROUZET;

- $\quad$ pH probe HANNA INSTRUMENTS 1001 and pH indicator;

- $\quad$ speed variator SCHNEIDER ATV 12.

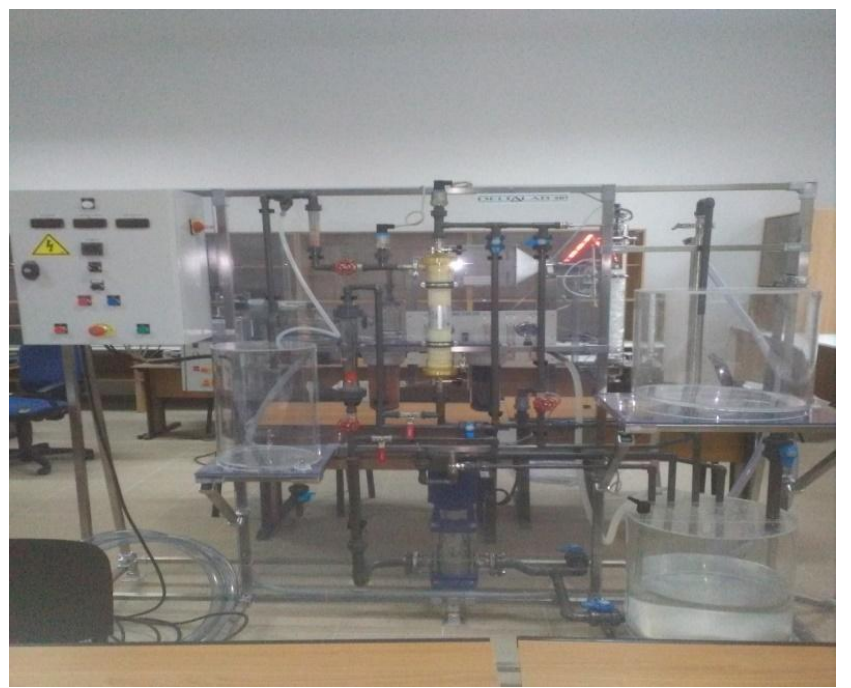

Fig. 12. Ultrafiltration of waste water with organic hollow fiber membrane module [57].

The membrane module of ultra-filtration system MP 90 comprises (Figure 13) [57]:

- organic fiber membrane made of polyacrylonitrile:

- initial flow into water under a membrane transverse pressure of 1 bar: $90 \mathrm{~L} / \mathrm{h}$;

- filtration area: $0.6 \mathrm{~m}^{2}$;

- inner diameter of the fiber: $0.8 \mathrm{~mm}$;

- external diameter of the fibers: $1.4 \mathrm{~mm}$;

- module length: $552 \mathrm{~mm}$;

- module outer diameter: $60 \mathrm{~mm}$;

- maximum inlet pressure: 5 bar;

- maximum trans membrane pressure: 3 bar;

- maximum temperature: $500 \mathrm{C}$;

- pH range: 2-10.

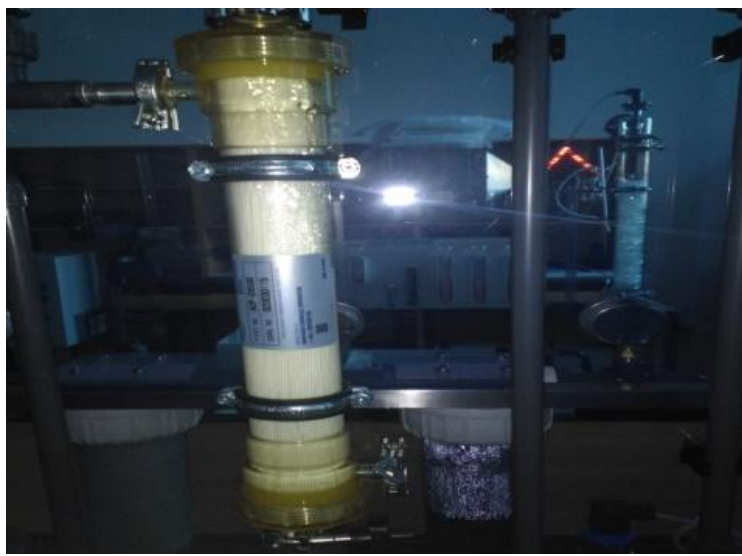

Fig. 13. Organic membrane module of hollow fibers [57]. 
This type of plant (Figure 12) serves the ultrafiltration process and one of the many directions is the recovery of proteins in the food industry, respectively milk processing. At the same time, it can be tested on the extraction of the various substances added to the wastewater supply, such as bentonite, humic acid, etc.

Following the many experiments, the following curves can be drawn:

- flow of permeate to transmembrane pressure: $\mathrm{QP}=\mathrm{f}(\mathrm{PTM})$;

- flow of permeate to tangential velocity: $\mathrm{QP}=\mathrm{f}(\mathrm{Vt})$;

- flow of the permeate to the concentration factor: $\mathrm{QP}=\mathrm{f}(\mathrm{VCF})$;

- permeate flow according to time and concentration: $\mathrm{QP}=\mathrm{f}(\mathrm{t}, \mathrm{VCF})$ in "continuous" mode;

- permeate flow as a function of temperature: $Q P=f(T)$;

- permeate flow as a function of time: $\mathrm{QP}=\mathrm{f}(\mathrm{t})$.

Cunyu Li et al. [12] have tested an organic fiber-like membrane similar to that of Figure 12 in an ultrafiltration process. The operating surface of the membrane was $0.5 \mathrm{~m}^{2}$ with adjustable pressure and flow.

First, the membrane was tested with deionized water, then a concentration of saponin solution of $10 \mathrm{mg} / \mathrm{L}$ deionized water was made. Tests with low pressures and 0.01 were performed respectively; $0.05 ; 0.1 ; 0.15 ; 0.2$; $0.25 \mathrm{MPa}$. Following the experiments, permeate samples were taken and analyzed on a chromatograph [12]. Then the retention rate was calculated according to the molecular weight.

The results showed that with the increase in molecular weight, the degree of retention of the material in the filtered water decreases. In other words, particle deposition in membrane pores affects permeate flow and increases membrane pressure [56].

Similar to dairy ultrafiltration, where whey casein retention was required, Mohammad et al. good results have been obtained with regard to the efficiency of removing toxic substances from juices [49].

With regard to these results, it is estimated that the module shown in Figure 13 may have a yield at least similar to that presented by the researchers presented in the above discussion, since the hollow fiber membrane of the MP 90 ultrafiltration plant has no degree of aging [57].

\section{CONCLUSIONS}

Although fouling is the major disadvantage in membrane technology, the countercurrent wash method has shown a high cleaning efficiency, especially when using oils that can increase this membrane dirt. However, countercurrent washing may have a disadvantage because it can increase pores in the membrane, so it can change the membrane structure that leads to a new dependence between the operating parameters [50]. In this case, the operating conditions must be changed.

This type of membrane cleaning has demonstrated the removal of the material both from the pores and from inside them that have accumulated during the filtration processes during the experiments.

Through hollow fiber membranes, very good results in water filtration with different compounds are obtained when they are constantly cleaned by different processes: countercurrent washing or chemical solutions.

The experiments performed were related to the dependence of the plant parameters, the feed rate, the pressure of the pump, the concentration of the permeate obtained, its volume and the parameters of the membrane: membrane type, pore size, distribution, transmembrane pressure, etc.

Information on the dependence of parameters was collected in a set time, and then the results obtained were compared by changing the working conditions after a certain period of experimentation.

Research to date has shown that membrane technology has a significant impact on the recovery of water sources only if it is well understood; Fortunately, the many advantages over time have sparked a number of concerns that emphasize both concern for water sources and the satisfaction of operating in this area of study, research and profoundness. Another advantage of membranes is the possibility of recovering the concentrate for reuse. 
This review has successfully demonstrated several application directions for the hollow fiber membrane module in the ultrafiltration field since most experiments have shown an increased efficiency in the degree of material retention on the membrane surface and at the same time the operating time with the same membrane was prolonged.

\section{REFERENCES}

[1] Barsan, N., Nedeff, V., Temea, A., Mosnegutu, E., Chitimus, A.D., Tomozei, C., A perspective for poor wastewater infrastructure regions: a small-scale sequencing batch reactor treatment system, Chemistry journal of Moldova, vol. 12, no. 1, 2017, p. 61-66.

[2] Barsan, N., Nedeff, V., Mosnegutu, E., Panainte, M., Heat balance components of a small sequencing batch reactor applied for municipal wastewater treatment, Environmental engineering\&management journal, vol. 11, no. 12, 2012, p. 2133-2140.

[3] Tirtoaca Irimia, O., Tomozei, C., Panainte, M., Mosnegutu, E.F., Barsan, N., Efficiency of filters with different filtering materials: comparative study in water treatment, Environmental engineering \& management journal, vol. 11, no. 12, 2012, p. 2133-2140.

[4] Turcu, M., Bârsan, N., Moșneguțu, E., Dascălu, M., Chiţimuş, D., Radu, C., Application of the flocculation process in the industrial wastewater treatment, Environmental engineering \& management journal, vol. 15, no. 3, 2016.

[5] Bârsan, N., Nedeff, V., Lazăr, G., Current stage of domestic wastewater treatment in small plants, Journal of engineering studies and research, vol. 17, no. 4, 2011, p. 13-23.

[6] Shannon, M.A., Bohn, P.W., Elimelech, M., Georgiadis, J.G., Marĩas, B.J., Mayes, A.M., Science and technology for water purification in the coming decades, Nature, vol. 452, 2008, p. 301-310.

[7] Ng, L.Y., Mohammad, A.W., Leo, C.P., Hilal, N., Polymeric membranes incorporated with metal/metal oxide nanoparticles: A comprehensive review, vol. 308, 2013, p. 15-33.

[8] Baker, R.W., Membrane Technology and Applications, 2012.

[9] Yin, J., Deng, B., Polymer-matrix nanocomposite membranes for water treatment. Journal of membrane science, 2015, p. 256-275.

[10] Bu-Rashid, K.A., Czolkoss, W., Pilot tests of multibore uf membrane at addur swro desalination plant, Bahrain. Desalination, vol. 203, 2007, p. 229-242.

[11] Peng, N., Teoh, M.M., Chung, T.S., Koo, L.L., Novel rectangular membranes with multiple hollow holes for ultrafiltration, Journal of membrane science, vol. 372, 2011, p. 20-28.

[12] Sung, J.H., Kim, H.S., Jin, H.J., Choi, H.J., Chin, I.J., Nanofibrous membranes prepared by multiwalled carbon nanotube/poly(methyl methacrylate) composites. Macromolecules, vol. 37, 2004, p. 9899-9902.

[13] Katsoufidou, K., Yiantsios, S.G., Karabelas, A.J., A study of ultrafiltration membrane fouling by humic acids and flux recovery by backwashing: experiments and modeling, J. membr. sci., vol. 266, 2005, p. 40-50.

[14] Visvanathan, C., Ben Aim, R., Parameshwaran, K., Membrane separation bioreactors for wastewater treatment, Crit. Rev. Environ. sci. technol., vol. 30, 2000, p. 1-48.

[15] Liao, B.Q., Bagley, D.M., Kraemer, H.E., Leppard, G.G., Liss, S.N., A review of biofouling and its control in membrane separation bioreactors, Water env. res., vol. 76, 2004, p. 425-436.

[16] Akhondi, E., Wicaksana, F., Fane, A.G., Evaluation of fouling deposition, fouling reversibility and energy consumption of submerged hollow fiber membrane systems with periodic backwash, J. membr. sci., vol. 452, 2014, p. 319-331.

[17] Peng, N., Widjojo, N., Sukitpaneenit, P., Teoh, M.M., Lipscomb, G.G., Chung, T.S., Lai, J.Y., Evolution of polymeric hollow fibers as sustainable technologies: past, present, and future, Prog. polym. sci., vol. 37, 2012, p. 1401-1424.

[18] Lim, S.K., Setiawan, L., Bae, T.H., Wang, R., Polyamide-imide hollow fiber membranes crosslinked with amine-appended inorganic networks for application in solventresistant nanofiltration under low operating pressure, J. memb. sci., vol. 501, 2016, p. 152-160.

[19] Vandezande, P., Gevers, L.E.M., Vankelecom, I.F.J., Solvent resistant nanofiltration: separating on a molecular level, Chem. soc. rev., vol. 37, 2008, p. 365-405.

[20] Marchetti, P., Jimenez Solomon, M.F., Szekely, G., Livingston, A.G., Molecular separation with organic solvent nanofiltration: a critical review, Chem. rev., vol. 114, 2014, p. 10735-10806.

[21] Xing, D.Y., Chan, S.Y., Chung, T.S., The ionic liquid [EMIM] OAc as a solvent to fabricate stable polybenzimidazole membranes for organic solvent nanofiltration, Green Chem., vol. 16, 2014, p. 1383-1392.

[22] Hermia, J., Constant pressure blocking filtration laws - application to power-law Non-Newtonian Fluids, Trans. Inst. chem. eng., vol. 60, 1982, p.183-187. 
[23] Mochizuki, S., Zydney, A.L., Theoretical analysis of pore size distribution effects on membrane transport, J. membr. sci., vol. 82, 1993, p. 211-227.

[24] Mansourizadeh, A., Ismail, A.F., Effect of additives on the structure and performance of polysulfone hollow fiber membranes for $\mathrm{CO}_{2}$ absorption, J. membr. sci., vol. 348, 2010.

[25] Peng, N., Chung, T.S., Li, K.Y., The role of additives on dope rheology and membrane formation of defectfree Torlon ${ }^{\circledR}$ hollow fibers for gas separation, J. membr. sci., vol. 343, 2009.

[26] Tsai, H.A., Ciou, Y.S., Hu, C.C., Lee, K.R., Yu, D.G., Lai, J.Y., Heat-treatment effect on the morphology and pervaporation performances of asymmetric PAN hollow fiber membranes, J. membr. sci., vol. 255, 2005.

[27] Zhou, F.B., Koros, W.J., Study of thermal annealing on Matrimid fiber performance in pervaporation of acetic acid and water mixtures, Polymer, vol. 47, 2006.

[28] Jiang, L.Y., Chung, T.S., Rajagopalan, R., Dehydration of alcohols by pervaporation through polyimide Matrimid asymmetric hollow fibers with various modifications, Chem. eng. sci., vol. 63, 2008.

[29] Qiu, W. Kosuri, M., Zhou, F., Koros, W.J., Dehydration of ethanol-water mixtures using asymmetric hollow fiber membranes from commercial polyimides, J. membr. sci., vol. 327, 2009.

[30] Xu, Z.K., Dai, Q.W., Liu, Z.M., Kou, R.Q., Xu, Y.Y., Microporous propylene hollow fiber membranes. II. Pervaporation separation of water/ethanol mixtures by the poly (acrylic acid) grafted membranes, J. membr. sci., vol. 214, 2003.

[31] Kung, G., Jiang, L.Y., Wang, Y., Chung, T.S., Asymmetric hollow fibers by polyimide and polybenzimidazole blends for toluene/iso-octane separation, J. membr. sci., vol. 360, 2010, p. 303-314.

[32] Jiang, L.Y., Chung, T.S., Rajagopalan, R., Dehydration of alcohols by pervaporation through polyimide Matrimid asymmetric hollow fibers with various modifications, Chem. eng. sci, vol. 63, 2008.

[33] Ginger, M.R., Grigor M.R., Comparative aspects of milk caseins, Compos. biochem. phys. B, vol. 124, 1999, p. 133-145.

[34] Cabasso, I., Klein, E., Smith, J.K., Polysulfone hollow fibers. I. Spinning and properties, J. appl. polym. sci., vol. 20, 1976, p. 2377-2394.

[35] Aptel, P., Abidine, N., Ivaldi, Lafaille, J.P., Polysulfone hollow fibers-effect of spinning conditions on ultrafiltration properties, J. membr. sci., vol. 22, 1985, p. 199-215.

[36] Cassano, A., Tasselli, F., Carmela, C., Corleone, V., PAN hollow fibre membranes with triacetyl-bcyclodextrin for the removal of pesticides from citrus essential oils, Separation and purification technology, vol. 116, 2013, p. 124-130.

[37] Cao, C., Chung, T.S., Chen, S.B., Dong, Z.J., The study of elongation and shear rates in spinning process and its effect on gas separation performance of poly(ether sulfone) (PES) hollow fiber membranes, Chem. eng. sci., vol. 59, 2004, p. 1053-1062.

[38] Krol, J., Boerrigter, M., Koops, G.H., Polyimide hollow fiber gas separation membranes: preparation and the suppression of plasticization in propane/propylene environments, J. memb. sci., vol. 184, 2011, p. 275-286.

[39] Jiang, L.Y., Chung, T.S., Kulprathipanja, S., An investigation to revitalize the separation performance of hollow fibers with a thin mixed matrix composite skin for gas separation, J. memb. sci., vol. 276, 2006, p. 113125.

[40] See Toh, Y.H., Lim, F.W., Livingston, A.G., Polymeric membranes for nanofiltration in polar aprotic solvents, J. memb. sci., vol. 301, 2007, p. 3-10.

[41] Tham, H.M., Wang, K. Y., Hua, D., Japip, S., Chung, T.S., From ultrafiltration to nanofiltration: Hydrazine cross-linked polyacrylonitrile hollow fiber membranes for organic solvent nanofiltration, Journal of membrane science, vol. 542, 2017, p. 289-299.

[42] Peng, N., Chung, T.S., Wang, K.Y., Macrovoid evolution and critical factors to form macrovoid-free hollow fiber membranes, J. memb. sci., vol. 318, 2008, p. 363-372.

[43] Wang, K.Y., Li, D.F., Chung, T.S., Chen, S.B., The observation of elongation dependent macrovoid evolution in single-and dual-layer asymmetric hollow fiber membranes, Chem. eng. sci., vol. 59, 2004, p. 46574660

[44] Cao, C., Chung, T.S., Chen, S.B., Dong, Z.J., The study of elongation and shear rates in spinning process and its effect on gas separation performance of poly(ether sulfone) (PES) hollow fiber membranes, Chem. Eng. Sci., vol. 59, 2004, p. 1053-1062.

[45] Smolders, S.A., Reuvers, A.J., Boom, R.M., Wienk, I.M., Microstructures in phase-inversion membranes. Part 1. formation of macrovoids, J. Memb. Sci., vol. 73, 1992, p. 259-275.

[46] Parameshwaran, K. Fane, A.G., Cho, B.D., Kim, K.J., Analysis of microfiltration performance with constant flux processing of secondary effluent, Water res., vol. 35, 2001, p. 4349-4358.

[47] Cassano, A., Tasselli, F., Conidi, C., Drioli, E., Corleone, V., Separation and purification technology, vol. 116, 2013, p. 124-130. 
[48] Fontananova, E., Di Profio, G., Curcio, E., Giorno, L., Drioli, E., Functionalization of polymeric membranes by impregnation and in situ cross-linking of a PDMS/ $\beta$-cyclodextrin network, J. incl. phenom. Macro., vol. 57, 2007, p. 537-543.

[49] Mohammad, A., Ng, C., Lim, Y., Ng, G., Ultrafiltration in food processing industry: Review on application, membrane fouling, and fouling control, Food and bioprocess technology, vol. 5 no. 4, 2013, p. 1143-1156.

[50] Su, S.K., Liu, J.C., Wiley, R.C., Cross-flow microfiltration with gas backwash of apple juice, Journal of food science, vol. 58, no. 3, 1993, p. 638-641.

[51] Ben Amar, R., Gupta, B.B., Jaffrin, M.Y, Apple juice clarification using mineral membranes: Fouling control by backwashing and pulsating flow, Journal of food science, vol. 55, no. 6, 1990, p. 1620-1625.

[52] Zhu, Z., Luo, J., Ding, L., Bals, O., Jaffrin, M.Y., Vorobiev, E., Chicory juice clarification by membrane filtration using rotating disk module, Journal of food engineering, vol. 115, no. 2, 2013, p. 264-271.

[53] Alvarez, S., Alvarez, R., Riera, F.A., Coca, J., Influence of depectinization on apple juice ultrafiltration Colloids and Surfaces A, Physicochemical and Engineering Aspects, vol. 138 no. 2-3, 1998, p. 377-382.

[54] Zhang, G., Zhașng, J., Wang, L., Meng, Q., Wang, J., Fouling mechanism of low-pressure hollow fiber membranes used in separating nanosized photocatalysts, Journal of membrane science, vol. 389, no. 1, 2012, p. 532-543.

[55] Jawor, A., Hoek, E.M.V., Removing cadmium ions from water via nanoparticle-enhanced ultrafiltration, Environmental science and technology, vol. 44, 2010, p.2570-2576.

[56] Li, C., Ma,Y., Li, H., Peng, G., Chinese, journal of chemical engineering, vol. 25, no. 1, 2017, p. 62-67.

[57] Technical Bulletin, ultrafiltration pilot MP 90, Version AM-03/2014. 